\title{
Neopragmatismo de Richard Rorty $x$ teoria da ação comunicativa de Jürgen Habermas
}

\author{
Richard Rorty's neopragmatism $\times$ Jürgen Habermas' \\ theory of communicative action
}

*Manfredo Araújo de Oliveira

\begin{abstract}
Resumo: O presente artigo busca apresentar duas das formas mais relevantes de pragmatismo que surgiram no século XX e que possuem a pretensão de articular um novo paradigma para a filosofia. Em primeiro lugar, o neopragmatismo de Richard Rorty, que evita qualquer tipo de fundamentação última do conhecimento e considera a filosofia um saber crítico e construtivo que está a serviço das pequenas causas do dia a dia. E, em segundo lugar, a teoria da ação comunicativa, de Jürgen Habermas, a qual busca um sentido incondicionado para os mundos vividos e, com isso, apresenta uma filosofia com pretensões de universalidade. Assim, este artigo pretende mostrar as diferenças entre as posições pragmáticas desses dois filósofos quanto ao papel da justificação dos contextos concretos de ação.
\end{abstract}

Palavras-chave: pragmatismo, paradigma, filosofia, neopragmatismo, Teoria da Ação Comunicativa.

\begin{abstract}
This paper aims to present two of the most relevant forms of pragmatism that emerged in the twentieth century and that have the pretension to articulate a new paradigm for philosophy. Firstly the neopragmatism of Richard Rorty, which avoids any kind of ultimate grounding of knowledge and considers philosophy a critical and constructive knowledge that is at the service of small claims every day. And secondly the theory of communicative action of Jürgen Habermas, which search a meaning to the unconditioned lived worlds and thereby presents a philosophy with pretensions to universality. Thus, this article aims to show the differences between the pragmatic positions
\end{abstract}

* Professor Titular do Curso e do Programa de Pós-Graduação em Filosofia da Universidade Federal do Ceará (UFC), Fortaleza, Brasil. Endereço postal: Universidade Federal do Ceará (UFC), Fortaleza, Brasil. Instituto de Cultura e Arte (ICA). Curso de Graduação em Filosofia. Av. da Universidade, 2995, 2 Andar, Benfica. Fortaleza, CE - CEP 60020-181. $<$ manfredo.oliveira@uol.com.br>.

\begin{tabular}{|l|l|l|l|l|l|}
\hline Veritas & Porto Alegre & v. 58 & n. 1 & jan./abr. 2013 & p. 37-60 \\
\hline
\end{tabular}


of these two philosophers about the role of justification of the concrete contexts of action.

Keywords: pragmatism, paradigm, philosophy, neopragmatism, Theory of Communicative Action.

\section{Introdução}

O Pragmatismo que, hoje, em diferentes variantes apresenta-se como uma forma de filosofia capaz de enfrentar os desafios próprios de nosso tempo, ${ }^{1}$ certamente, pode ser compreendido, do ponto de vista de suas raízes, como sendo devedor, de um lado, ao pragmatismo clássico dos norte-americanos (Peirce, Dewey, James, Schiller), por outro lado, às filosofias que emergiram da reviravolta pragmática do Wittgenstein das "Investigações Filosóficas". ${ }^{2}$ A segunda fase do pensamento de Wittgenstein vai caracterizar-se por uma crítica profunda ao ideal de uma linguagem unitária, universal, para a tradição, a única forma de reprodução do mundo (paradigma da representação) e pela procura de um horizonte novo de compreensão da linguagem humana. Para ele, a postura adequada vai concentrar-se na consideração do próprio uso da linguagem (PhU 7), portanto, na própria práxis linguística: a palavra, vista em si mesma, é carente de significado; é através de seu uso que ela, ao assumir uma função determinada na ação linguística, passa a ter, igualmente, um significado.

Para Wittgenstein, não podemos apelar para um reino pré-existente de significações para resolver nossos problemas a respeito do significado das expressões linguísticas; basta apelar para uma forma determinada de agir linguisticamente. Por isto, a compreensão do significado de uma expressão linguística pressupõe o conhecimento do contexto de seu uso. Desta forma, unicamente na esfera da práxis da linguagem, constituise o "mundo" como o espaço comum que torna possível as interações entre os sujeitos. Nesta perspectiva, a linguagem manifesta-se como um evento que é o todo (PhU 7) da unidade entre a linguagem e as atividades executadas através dela.

A linguagem faz parte de uma forma de vida e isto significa dizer que falar é a realização de um ato socialmente regrado, é uma maneira de instituir interações entre sujeitos, portanto, uma forma determinada de viver em sociedade. Se o ser humano possui a capacidade de falar como

Cf. DE WAAL, C. Sobrepragmatismo. São Paulo: Loyola, 2007, p. 238.

2 Cf. WITTGENSTEIN L. Philosophische Untersuchungen. Frankfurt am Main: Suhrkamp, 1967 (Abreviado: PhU). 
algo que é constitutivo de seu ser, sua atualização, contudo, exige uma aprendizagem das atividades, das normas e dos papéis pressupostos pelo falar, o que manifesta ser a linguagem uma habilidade que se adquire historicamente.

O pressuposto central desta concepção é de que a linguagem radicase num acordo prévio a respeito de um sistema de normas e convenções sociais, ou seja, passa, aqui, para o primeiro plano, o caráter prático e intersubjetivo da linguagem humana. ${ }^{3}$ A partir disso, a linguagem começa a ser entendida, em primeiro lugar, como ação social, que, por esta razão, só pode ser explicada como produção de uma comunidade de sujeitos. Ela é a mediação necessária no processo intersubjetivo de comunicação de tal modo que o ponto de referência de toda a filosofia, agora, é a comunidade de sujeitos em interação, sua práxis comum, realizada de acordo com regras determinadas originadas a partir do uso das palavras nas comunidades específicas. ${ }^{4}$

Formas linguísticas são, então, formas elementares de vida, que determinam a estrutura subjetiva e intersubjetiva do comportamento, do falar e do compreender. Estas regras são costumes, que chegam a se tornar fatos sociais reguladores, ou seja, instituições sociais. Tantas são as formas de vida existentes (PhU 19), tantos são os contextos da práxis humana, tantos são, consequentemente, os modos de uso da linguagem, portanto, os jogos de linguagem. Poder usar a linguagem significa estar capaz de inserir-se num processo de interação social simbólica de acordo com os diferentes modos de sua realização. A linguagem é o dado último precisamente como ação prática e fática e sua forma é constituidora do mundo. Numa intenção sistemática, vamos apresentar duas das formas mais importantes de pragmatismo que emergiram no século passado, que levantam a pretensão de articular um novo paradigma para a filosofia enquanto tal.

\section{A) O neopragmatismo de Richard Rorty}

O pragmatismo americano, que segundo J-P Cometti, ${ }^{5}$ é a filosofia mais solidamente enraizada na cultura americana, desenvolveu-se em

3 Isto vai significar, como viu Giannotti, uma enorme ampliação do campo da lógica e de sua tarefa. Ao invés de pretender construir uma linguagem ideal como padrão das linguagens quotidianas, o que a investigação lógica busca, agora, é explicitar, através de exemplos, as diferentes possibilidades de conexões e seus respectivos elementos. Cf. GIANNOTTI, J. A. Apresentação do Mundo. Considerações sobre o pensamento de Ludwig Wittgenstein. São Paulo: Companhia das Letras, 1995, p. 65 e ss.

4 Cf. SOUZA FILHO, D. M. de. Filosofia, Linguagem e Comunicação. São Paulo, 1984.

5 Cf. COMETTI, J-P. "Le Pragmatisme: de Peirce à Rorty". In: MEYER, M. (Org.). La Philosophie anglo-saxonne. Paris: PUF, 1994, p. 396. 
torno de uma filosofia do conhecimento, mas, desde o princípio, se afastou de concepções que tendem a privilegiar a busca de um fundamento no absoluto ou a de um modelo da razão, que determina a priori as possibilidades de busca e de descoberta. A ideia de que a crença situa-se ao mesmo tempo no começo e no fim da pesquisa é o cerne da oposição de Peirce a Descartes. O retorno recente ao pragmatismo foi, por sua vez, possibilitado por uma crítica forte ao empirismo, sobretudo o do Círculo de Viena, que se havia difundido muito nos Estados Unidos. Esta crítica começou com o texto famoso de Quine sobre os dois dogmas do empirismo ${ }^{6}$ e foi continuada por N. Goodman, W. Sellars e D. Davidson. ${ }^{7}$ É neste contexto que Rorty vai articular sua versão do pragmatismo e vai concentrar-se, em primeiro lugar, na crítica à metafísica.

Pode-se dizer que o pensamento central da metafísica, ${ }^{8}$ apresentado no Menon (82 b-85 b), é que o conhecimento humano não se limita ao conhecimento da experiência, mas que é possível chegar a um conhecimento objetivo do mundo através dos conceitos. Fundamento da verdade não é, então, o mundo material empírico, mas o mundo do pensamento, que apreende a estrutura inteligível do real. Desta forma, o espírito humano é compreendido como coextensivo ao mundo ${ }^{9}$ assim que as leis da lógica exprimem as leis que estruturam a própria realidade. Rorty interpreta esta postura do pensamento clássico como sendo a pretensão de captar, pela mediação do conceito, a forma e o movimento da natureza e da história o que, em última instância, desembocou na ideia de que o ser humano é capaz de descobrir como reparar a injustiça da história humana. ${ }^{10}$

Ele reputa esta tese como a doença subjacente a toda a tradição do pensamento ocidental, que só é curável partir da posição exatamente contrária: não existe uma realidade maior além daquela que se mostra no dia a dia e que pudesse garantir um horizonte de reconciliação e salvação para ação do ser humano em seu mundo. Daí porque sua proposta vai concentrar-se basicamente na tentativa de cura da humanidade da doença platônica, metafísica, o que deve ocorrer, segundo ele, através

6 Cf. QUINE, W. V. “Two Dogmas of Empiricism”. In: AUDI R. (Org.). Epistemology Contemporary Readings. London/New York: Routledge, 2002, p. 176-193.

7 Cf. COMETTI, J-P. op. cit., p. 446 e ss.

8 Cf. HÖSLE, V. Hegels "Naturphilosophie" und Platons "Timaios" - ein Sturkturvergleich. In: Philosophiegeschichte und objektiver Idealismus. München: Verlag C. H. Beck, 1996, p. 39 e ss.

9 A respeito da fórmula de adequação cf. ARISTÓTELES: Met. IV 7, 1011 b 26 e ss; De

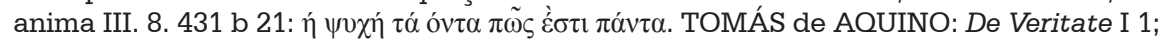
S.Th. I q. 16 a 2 ad 2; I q. 21 a 2 ad 2.

10 Cf. RORTY, R. Objectivity, Relativism and Truth. Philosophical Papers I, Cambridge Univ., 1991. 
de uma radicalização da postura da filosofia analítica que encontra seu cerne na reviravolta linguística. ${ }^{11}$

Na medida em que esta reviravolta plenifica-se através da reviravolta pragmática, manifesta-se a necessidade de renúncia a uma postura que a vinculou tacitamente à grande tradição do pensamento ocidental, ou seja, a de que ainda há verdades filosóficas a descobrir, que podem ser fundamentadas por meio de argumentos. Daí a conclusão: a primeira tarefa deve consistir na desconstrução da metafísica, no desmascaramento do platonismo, que parte da demonstração de que mesmo a filosofia analítica permaneceu presa à metafísica que combateu, o que confirma a tese de que toda nossa cultura está radicada nos mal-entendidos que remontam a Platão.

Esta nova postura é, para Rorty, o ponto de chegada da história da filosofia ocidental que se desenvolveu em três paradigmas básicos sem continuidade: o da metafísica em que o pensamento estava centrado nas essências das coisas (objetividade); o da teoria do conhecimento da modernidade que tem seu centro nas ideias, que são construções do espírito finito (subjetividade) e, por fim, o da filosofia da linguagem, cuja preocupação fundamental é as expressões linguísticas (intersubjetividade) em que a autoridade epistêmica passa do sujeito cognoscente, que gesta em si mesmo as medidas para a objetividade da experiência, para a práxis de justificação ${ }^{12}$ de uma comunidade linguística, pois, com a reviravolta linguística todas as explicações se radicam no primado da linguagem comum.

A filosofia analítica, ${ }^{13}$ que é fruto da reviravolta linguística, tem, para Rorty, de fato, uma postura antifundamentalista, o que, contudo, não garante sua ruptura com as teses da tradição. Ela articulou-se, em primeiro

11 Cf. RORTY, R. The linguistic Turn. Recent Essays in Philosophical Method. University of Chicago Press, Phoenix Edition, 1970.

12 A distinção entre justificação e verdade foi trabalhada por Putnam. Para ele, a aceitabilidade racional, saída de nossos critérios, não nos permite ir além da justificação, pois o fato de rejeitar que exista uma perspectiva externa coerente, uma teoria que seria simplesmente verdadeira em si mesma, independentemente das observações possíveis, não legitima a identificação entre verdade e aceitação racional: a verdade é uma propriedade inalienável das proposições o que a justificação não é. Se nossos conhecimentos não possuem jamais um caráter definitivo e, mesmo assim, temos razões para não os considerar arbitrários, não podemos ver unicamente nestas razões a fonte do que chamamos verdade de uma proposição. A verdade é uma idealização da aceitabilidade racional. Cf. PUTNAM, H. Reason, Truth and History, op. cit., p. 63 e ss.

13 Cf. RORTY, R. "Pragmatismo, Filosofia Analítica e Ciência". In: MARGUTTI PINTO, P. R. et alii (Orgs.). Filosofia Analítica, Pragmatismo e Ciência. Belo Horizonte: Editora UFMG, 1998, p. 17: "Mas antifundacionalismo não diminui a força do seguinte argumento: uma vez que a verdade é uma noção absoluta, e consiste em correspondência, deve haver uma natureza absoluta, intrínseca, independente da descrição feita, à qual a verdade deve corresponder". 
lugar, como uma crítica ao horizonte conceitual da filosofia moderna da subjetividade ${ }^{14}$ que fez a passagem da concepção clássica de uma racionalidade objetiva para uma racionalidade subjetiva conservando, porém, o horizonte conceitual clássico no que toca à concepção da realidade.

A realidade, agora, não é mais pensada como um mundo em si, independente de sua relação ao sujeito, mas como um mundo para nós, um mundo de objetos fenomênicos enquanto mundo de objetos representados dados ao sujeito. Numa palavra, aqui, a relação ao sujeito torna-se determinante. Neste novo quadro conceitual, a busca da verdade é interpretada como o esforço para fundamentar geneticamente a "adequação" entre a representação e o objeto a partir da certeza radicada em vivências evidentes.

Para Rorty, o objetivo fundamental da filosofia analítica consiste em mostrar a insuficiência do "horizonte mentalista" na concepção do conhecimento que é pensado como um produto de uma ação da autoconsciência do sujeito. Trata-se, nesta concepção, acima de tudo, de assegurar para a autoconsciência uma esfera especial de vivências para a qual o acesso é imediato e absolutamente certo, ainda que não seja direto o acesso do sujeito aos objetos, mas através de suas representações pela mediação da reflexão. Isto tem uma implicação fundamental, que constitui a nota característica da filosofia moderna: o dualismo entre sujeito e objeto, espírito e matéria, que abre o espaço para o ceticismo de tipo moderno e que, para Rorty, está sempre profundamente vinculado ao modelo mentalista.

De acordo com a perspectiva mentalista, que tem suas origens na filosofia antiga, mas que permaneceu intocada na filosofia moderna da consciência, a objetividade é assegurada pelo relacionamento correto do sujeito a seu objeto: o conceito, uma realidade do sujeito, corresponde ao que está fora, ao mundo objetivo. A mente é concebida, então, como um espelho contendo representações da realidade. Sem esta concepção da mente como um espelho, não teria sido possível pensar o conhecimento como representação da realidade. ${ }^{15}$ Esta imagem, para Rorty, surgiu no pensamento ocidental do desejo humano de dar fundamentos seguros ao conhecimento, o que é, para ele, um desejo totalmente equivocado, pois se radica em superstições e inseguranças que é melhor abandonar. ${ }^{16}$ Sua intenção é, então, conduzir a filosofia para longe da metáfora do

14 A respeito do tratamento da questão da verdade no horizonte da filosofia da consciência cf. LANDIM FILHO, R. “Sobre a Verdade”. In: Síntese Nova Fase, 20(63), 1993, p. 459-475.

15 Cf. RORTY, R. Der Spiegel der Natur. Frankfurt am Main: Suhrkamp, 1981, p. 12 e ss.

${ }^{16}$ Cf. RORTY, R. Der Spiegel der Natur. op. cit., p. 312 e ss. 
espelho ${ }^{17}$ o que conduz à ideia de que a aquisição do conhecimento é uma maneira de agir. ${ }^{18}$

A reviravolta linguística significou a compreensão de que a expressão linguística constitui a mediação necessária de todo e qualquer saber, condição irrecusável de todo acesso ao mundo, uma vez que em qualquer conhecimento de coisas, situações ou eventos no mundo se copenetram mutuamente linguagem e mundo. É por esta razão que a pergunta pelo que se pode conhecer implica sempre a pergunta pelo que se pode dizer. Esta reviravolta provoca uma mudança radical no sentido de "intersubjetivo" que, agora, não é mais entendido como o efeito de uma concordância observada de pensamentos ou representações de diferentes pessoas, mas é pensado a partir da ótica dos participantes num horizonte linguístico comum, no seio do qual já sempre se situam os membros de uma comunidade de comunicação. Nesta perspectiva, o ceticismo carece de sentido uma vez que os indivíduos socializados já sempre se situam no horizonte de seu mundo vivido, linguisticamente interpretado, e isto implica um pano de fundo de convicções intersubjetivamente partilhadas e confirmadas praticamente que tornam inteiramente sem sentido a dúvida total a respeito do acesso ao mundo. Elimina-se, aqui, completamente a dicotomia moderna do interior e do exterior.

Desta forma, nunca abandonamos a esfera da linguagem, o que nos traz, como consequência, uma concepção antifundamentalista de conhecimento, já que, como diz Rorty, algo só possui justificação com relação a outro algo já previamente aceito. É esta a razão pela qual nunca podemos, para além de nossa linguagem, crenças, conjecturas e opiniões, atingir um critério independente do critério da coerência de nossas afirmações. ${ }^{19}$ Numa palavra, na reviravolta pragmática, contextualisticamente interpretada, isto tem como consequência que não pode existir acesso a entidades do mundo independentemente do processo de entendimento intersubjetivo mediado pelo contexto linguístico dos diferentes mundos vividos das comunidades históricas. ${ }^{20}$

Assim, superado o representacionismo, a verdade reduz-se ao que se pode defender contra todos os inimigos, ${ }^{21}$ ou seja, ela é aquilo que nossos pares deixam-nos dizer. A verdade é, então, o consenso de

${ }_{17}$ Sua crítica central à metáfora do espelho não vem para De Waal dos clássicos do pragmatismo, mas da filosofia analítica. Cf. DE WAAL, C. Sobrepragmatismo, op. cit., p. 208: "Para Rorty, o ataque de Wilfrid Sellars ao dado e o ataque de Quine à necessidade causaram algumas sérias fissuras no espelho, fissuras que são impossíveis de reparar e não podem ser disfarçadas".

18 Cf. DE WAAL, C. Sobrepragmatismo, op. cit., p. 207.

19 Cf. RORTY, R. Der Spiegel der Natur, op. cit., p. 199 e s.

20 Cf. RORTY, R. Der Spiegel der Natur, op. cit., p.191.

21 Cf. RORTY, R. Der Spiegel der Natur, op. cit., p. 306 e ss. 
uma comunidade e não uma relação a uma realidade não humana ${ }^{22}$ e o pesquisador não pode pretender nada além da aprovação alheia de suas crenças. A filosofia, neste contexto, é, na realidade, um estudo sobre as vantagens e desvantagens comparativas das diferentes maneiras de conversar que a raça humana inventou. ${ }^{23}$ A meta da investigação não é, portanto, representar a realidade, mas sustentar crenças que nos são úteis para conseguir o que queremos. ${ }^{24} \mathrm{O}$ representacionismo é substituído por uma espécie de instrumentalismo. ${ }^{25}$

Enfim, o que fazemos quando achamos que adquirimos conhecimentos? "A resposta de Rorty é que estamos engajados numa conversação direcionada a gerar concordância - ou, ao menos, desacordo interessante - de uma maneira que nos ajude a enfrentar a vida". ${ }^{26}$ Em última instância, o que importa é nossa solidariedade com outros seres humanos na escuridão de nossa vida, uma solidariedade que é limitada à própria cultura, uma vez que não podemos escapar de nossa própria cultura e a única forma de não sermos totalmente determinados por ela é aquilo que Rorty denomina o "método da ironia": violar consciente e cuidadosamente as regras de nosso próprio vocabulário. Isto faz-nos conscientes da contingência e da fragilidade de nossos vocabulários e de nós mesmos. ${ }^{27}$

Não aparece, com clareza, em Rorty, a ideia de que já Kant, ${ }^{28} \mathrm{com}$ sua problemática da constituição dos objetos da experiência, fez uma crítica radical à concepção realista, ingênua da fórmula da adequação: o objeto não é simplesmente "em-si", pois é coconstituído pelo pensamento assim que o fundamento da verdade situa-se na aprioridade das leis do entendimento puro e estas condições subjetivas do pensamento têm validade objetiva na medida em que geram o objeto segundo a forma. Não há, portanto, acesso aos objetos do mundo sem a mediação das leis do entendimento, ou seja, sem a mediação da consciência. A postura pragmática, de qualquer forma, tem, para Rorty, enormes consequências na concepção da realidade e da verdade justamente porque não dá para pensar realidade e verdade sem linguagem. ${ }^{29}$

22 Cf. RORTY, R. Philosophical Papers. vol. I, Cambridge, 1991, p. 23.

${ }^{23}$ Cf. RORTY, R. Consequences of Pragmatism. Minneapolis: University of Minnesota Press, 1982, p. Xl.

${ }^{24}$ Cf. RORTY, R. Philosophy and Social Hope. London, 1999, p. 33.

25 Cf. DE WAAL, C. Sobrepragmatismo, op. cit., p. 213.

${ }^{26}$ Cf. DE WAAL, C. Sobrepragmatismo, op. cit., p. 217.

27 Cf. RORTY, R. Contingency, Irony and Solidarity. Cambridge, 1989, p. 73 e s.

${ }^{28}$ Cf. HÖFFE, O. "Anhang: Kritische Überlegungen zur Konsensustheorie der Wahrheit (Habermas)". In: Ethik und Politik. Grundmodelle und probleme der praktischen Philosophie. Frankfurt am Main: Suhrkamp, 1979, p. 258.

${ }^{29}$ É num horizonte análogo que Th. Kuhn entende a "realidade" estudada pelas ciências. Cf. AGUIAR, T. R. X de. "Realismo, Construtivismo e Progresso". In: MARGUTTI PINTO, P. R. et alii (orgs.), op. cit., p. 291: "O resultado é uma interessante forma de construtivismo: 
A primeira consequência é que a representação de objetos não é um modelo adequado para pensar o saber, pois compreendemos, agora, que se trata da captação de estados de coisas mediante sua articulação proposicional. ${ }^{30}$ a verdade não pode existir sem relação ao espírito humano, respectivamente à linguagem humana, de tal forma que, onde não há sentenças, não há verdade e, mais ainda, a verdade está unicamente em sentenças criticáveis que podem ser fundamentadas através de razões. Portanto, a verdade é exclusivamente uma propriedade de entidades linguísticas, ou seja, de sentenças.

Na teoria tradicional da verdade, a teoria da correspondência, o próprio conceito de verdade como correspondência implicava que a verdade tinha a ver com a realidade, com o mundo, portanto, tentava-se pensar, aqui, de alguma forma, uma relacionalidade implicada no próprio conceito de verdade. Portanto, para a tradição, uma sentença expressa alguma coisa, expressa uma relação entre linguagem e mundo e, desta forma, expressa um determinado setor do mundo em si. É justamente esta relacionalidade que parece desaparecer aqui e a linguagem enclausura-se em si mesma. Certamente que se pode perguntar se se pode dizer algo além do dizer sobre a própria linguagem, ${ }^{31}$ uma posição que ele mesmo não segue, pois acolhe, como diz do senso comum, duas entidades externas à linguagem: as "coisas do mundo" e uma certa forma de subjetividade. ${ }^{32}$

A reviravolta pragmática tornou, então, possível a superação da simples transferência da relação "sujeito-objeto" para a relação "sentençafato", pois foi justamente isto que fez a reviravolta linguística permanecer ligada à ideia de representação, e, portanto, à concepção de verdade como "espelho da natureza". Uma vez radicalizada a reviravolta linguística, a subjetividade das opiniões perde o controle conseguido através de uma confrontação com um mundo objetivo. ${ }^{33}$ Agora, entra em cena o controle

a realidade estudada pela ciência é - de uma maneira que o próprio Kuhn tem, reconhecidamente, dificuldade de precisar - determinada pelo paradigma corretamente adotado pela comunidade científica relevante".

30 Cf. HABERMAS, J. Wahrheit und Rechtfertigung. "Zu Richard Rortys pragmatischer Wende". In: Wahrheit und Rechtfertigung. Philosophische Aufsätze. Frankfurt am Main: Suhrkamp, 1999, p. 236 e ss.

31 Para Utz trata-se aqui de um "monismo linguístico". Cf. UTZ, K. Kontingenz Absolut. Richardd Rortys "Contingency, irony and solidarity" (mimeo). Tübingen, 2005, p. 9.

32 Cf. UTZ, K. Kontingenz Absolut, op. cit., p. 11.

33 Já no caso de Peirce, a associação da crença, enquanto regra, com a ação sob a determinação do hábito permite ao pragmatismo fazer economia da representação substituindo a relação externa da ideia e do mundo, ou do espírito e do real, por uma relação interna da crença e do hábito, isto é, da regra. Daí a crítica aos dualismos e a uma "teoria contemplativa do conhecimento" desenvolvida também por James e Dewey. Cf. COMETTI, J-P. op. cit., p. 398. 
pela mediação de uma comunidade pública de comunicação ${ }^{34}$ e, neste contexto, o mundo objetivo deixa de ser algo que possa ser reproduzido e torna-se um simples ponto comum de referência de um processo de entendimento entre os membros de uma comunidade determinada de comunicação, que se entendem entre si sobre algo. Transforma-se, assim, radicalmente o conceito de objetividade que, agora, é entendida como o maior acordo intersubjetivo possível, o que leva Rorty à afirmação de uma de suas teses fundamentais: a verdade é muito mais feita do que encontrada, já que é produto de criações humanas contingentes. ${ }^{35}$

Numa palavra, conhecimento não é mais pensado como espelho da natureza, correspondência entre sentença e fato, porque, na linguagem de Rorty, não existe contato anterior à linguagem, que permitiria meter o dedo sobre o que é um objeto em si mesmo em oposição ao que ele é à luz das descrições variadas que lhe damos, ${ }^{36}$ ou seja, não podemos comparar linguagem e mundo, mas só podemos comparar linguagens ou metáforas com outras linguagens ou outras metáforas, mas não com algo para além da linguagem. Isto leva a uma perda de sentido de uma série de conceitos e distinções básicas do pensamento da tradição: assim, perdem o sentido conceitos como natureza intrínseca das coisas, essência, verdade, a distinção entre significado e fatos, entre essencial e acidental, entre central e periférico, absolutismo e relativismo, racionalidade e irracionalidade, etc. ${ }^{37}$ Para Rorty, existe, então, uma dicotomia completa entre representacionismo e "conversacionalismo" de tal modo que a investigação não tem mais como objetivo dizer como as coisas realmente são, "mas para assegurar que a conversação continue, preferivelmente em lugares novos e excitantes". ${ }^{38}$

O conhecimento passa a ser pensado como um processo intersubjetivo de entendimento no qual a linguagem é considerada não apenas como a forma gramatical de apresentação do mundo, mas em sua dimensão comunicativa. Ele efetiva-se, então, no seio do mundo vivido como espaço público, intersubjetivamente partilhado, de interações e tradições entrelaçadas em redes simbólicas. Aqui, o diálogo entre pessoas (modelo comunicativo, processo intersubjetivo de entendimento) põese no lugar da contraposição sentença-fato (modelo representacionista, relação linguagem-mundo), ${ }^{39}$ o que revela o caráter ilusório do conceito

${ }^{34}$ Cf. KOGLER, H-H. Die Macht des Dialogs. Kritische Hermeneutik nach Gadamer, Foucault und Rorty. Stuttgart, 1991.

35 Cf. RORTY, R. Solidarität oder Objektivität? Stuttgart, 1988, p. 14-15.

${ }^{36}$ Cf. RORTY, R. Science et Solidarité. L 'Eclat, Combas, 1990, p. 9.

37 Cf. UTZ K. Kontingenz Absolut, op. cit., p. 1-2.

38 Cf. DE WAAl, op. cit., p. 232.

39 Para Habermas, a relação vertical ao mundo de sentenças sobre algo dobra-se à relação horizontal do estar junto aos participantes de uma comunidade de comunicação. 
tradicional de verdade ${ }^{40}$ como correspondência entre o representante e o representado, uma vez que ela implicaria a linguagem sair da linguagem. Desaparece, por isso, a exigência de espelhar a realidade ${ }^{41} \mathrm{e}$ as únicas exigências provêm do processo comunicativo: ${ }^{42}$ as questões da justificação não são mais questões da relação entre ideias ou palavras e objetos da natureza, mas de conversa, de prática social. Para Rorty ${ }_{13}{ }^{43}$ os pragmatistas de nenhuma forma apelam a uma teoria sobre a natureza da realidade, do conhecimento ou do homem, afirmando que nada existe como verdade ou bem. ${ }^{44}$ Isto de forma alguma implica, para ele, uma teoria subjetivista ou relativista da verdade ou do bem, porque o que eles desejam é simplesmente mudar de tema.

O elemento inteiramente novo é que a autoridade epistêmica transferese de um sujeito que representa o mundo objetivo para uma comunidade de sujeitos que se entendem entre si a partir da base comum de um mundo vivido, compartilhado diante do qual cada um justifica suas concepções. Conhecido é então o que é aceito como racional segundo os critérios da práxis exercida pela comunidade em questão. Isto provoca uma reviravolta radical na concepção de conhecimento: a objetividade da experiência cede o lugar à intersubjetividade da compreensão que é, em princípio, mutável uma vez que podem ser outros as crenças e os valores do universo simbólico que funda o entendimento recíproco entre os sujeitos. ${ }^{45}$

A intersubjetividade do mundo vivido reprime a objetividade de um mundo contraposto ao qual está um sujeito solitário. Cf. HABERMAS, J. Wahrheit, op. cit., p. 241.

40 Rorty sugere que apaguemos de nossa mente noções como verdade, erro, aparência e realidade. Cf. RORTY R. "Nietzsche, Sócrates e o Pragmatismo". In: VIDAL, V.; CASTRO, S. de (Org.). A questão da Verdade: da metafísica moderna ao pragmatismo. Rio de Janeiro: 7 Letras, 2006, p. 21: "Essas noções podem ser substituídas por noções tais como 'crenças vantajosas para certos propósitos, mas não para outros' e 'uma descrição de coisas úteis para certos tipos de pessoas, mas não para outros'. Estas são noções completamente pragmáticas, noções que abandonaram inteiramente a metáfora da correspondência".

${ }^{41}$ Que, aliás, parece não importar mais para Rorty. Cf. DE WAAL, C. op. cit., p. 212: "Essa conexão com o mundo está ausente, ou, na melhor das hipóteses, bem disfarçada na versão de Rorty. De fato, com seu único foco na concordância e nos constrangimentos conversativos, a interpretação de Rorty mina a própria distinção que Peirce procurou traçar entre o método a priori e o metido científico".

42 Cf. RORTY, R. Cosequences of Pragmatism (Essays 1972-1980). Minneapolis: Univ. of Minnesota Press, 1982, p. 165.

43 Cf. RORTY, R. Cosequences of Pragmatism, op. cit., p. XIII e s. A respeito da discussão de Rorty com Davidson a este respeito cf. PEREIRA, A. M. Lendo Rorty Lendo Davidson, In: MARGUTTI PINTO, P. R. et alii (org.), op. cit., p. 265-275.

44 No seio do pragmatismo, S. Haack discorda radicalmente da posição de Rorty na medida em que defende a tese de que um investigador genuíno quer mesmo a reposta para suas perguntas, isto é, ele está interessado em descobrir como as coisas realmente são. Cf. HAACK, S. Manifesto of a Passionate Moderate. Chicago, 1998, p. 9.

45 Cf. RORTY, R. Contingency, Irony and Solidarity. Cambridge: Cambridge Univ. Press, 1989. 
Para Rorty, a linguagem é contingente, o eu e a comunidade são igualmente contingentes. Assim, a contingência constitui o princípio do pensar de modo que a referência a normas absolutas é apenas um sonho inútil quando se considera a condição humana que é a condição de finitude. A tradição falava de normas transcendentes ${ }^{46}$ que nos são inacessíveis e cuja posse, por parte dos filósofos, legitimou, no passado, a supremacia específica da filosofia na discussão das coisas humanas. Ora, não existindo este acesso, o pragmatismo vai atribuir à filosofia uma função mais humilde, ligada às tarefas cotidianas da vida, sem privilégio nem supremacia frente a outras formas de discussão, a serviço, portanto, de outras causas, as pequenas causas do dia a dia com uma tarefa ao mesmo tempo crítica e construtiva. O que numa cultura pós-filosófica, no sentido de um adeus a uma filosofia com motivos transcendentes, fundacionais, essencialistas, irá desaparecer é a casta dos profissionais em filosofia, ciosa de seus privilégios.

Ao invés, então, de normas transcendentes só resta a solidariedade de nossas crenças e valores, de nossas preferências e de nossas escolhas no contexto compartilhado de nossas formas de vida. Isto, contudo, para ele, não nos dirige ao relativismo que é uma postura essencialmente vinculada ao modelo representacionista do conhecimento. Uma consequência imediata da nova concepção é que a justificação depende sempre de critérios diferentes de acordo com os contextos históricos. Isto exige de nós que abandonemos nossa preocupação com a objetividade e tornemonos satisfeitos com a intersubjetividade. ${ }^{47}$ São enormes as consequências no que diz respeito à problemática da verdade: por não ser o conhecimento um espelho da natureza, mas algo que está fundamentalmente imbricado com a práxis dialogal e o contexto social, então a crítica das diferentes formas de práxis social é destituída de qualquer sentido, já que estamos presos pelos contextos simbólicos e qualquer tentativa de transcendência a eles significa um retorno à postura fundamentalista. ${ }^{48}$

A reviravolta pragmática fez desaparecer a dúvida a respeito da existência de um mundo independente de nossas descrições, por outro lado, acentuou o caráter falível de todo saber e a necessidade de sua legitimação num contexto em que a medida da objetividade do

${ }^{46}$ Cf. RORTY, R. Consequences, op. cit.

47 Cf. RORTY, R. Pragmatismo, op. cit., p. 23.

48 Cf. RORTY, R. Pragmatismo, op. cit., p. 28: "Desistir da ideia de que a filosofia aproximase da Verdade e interpretá-la como fez Dewey é conceder primazia à imaginação sobre o intelecto argumentativo, e ao gênio sobre o profissionalismo". Para Margutti, os céticos pirrônicos se caracterizam pelo abandono da investigação filosófica para se dedicar aos afazeres práticos, "um domínio em que não ocorrem dúvidas radicais". Margutti não vê muita diferença entre a descrição do ironista rortyano e este tipo de ceticismo. Cf. MARGUTTI PINTO, P. R. Pragmatismo, Ironismo, op. cit., p.33. 
conhecimento é a própria práxis pública de justificação de que decorre a pergunta fundamental se ainda é possível separar a verdade de seu contexto de justificação ${ }^{49}$. Numa palavra, estabelecido que é impossível ir além do horizonte linguístico de opiniões justificadas, como se combina esta tese fundamental da reviravolta pragmática com a intuição de que sentenças verdadeiras levantam a pretensão de dar conta dos fatos do mundo. O desafio central do contextualismo de Rorty está aqui: relacionar verdade e justificação.

\section{B) O pragmatismo transcendental de Jürgen Habermas}

A fase atual do pensamento ocidental, que constitui, segundo Habermas, o questionamento mais radical a toda a tradição, é caracterizada por dois desafios teóricos fundamentais: a) A questão ontológica do naturalismo. Trata-se de pensar como é possível compatibilizar a normatividade irrecusável de um mundo vivido, linguisticamente estruturado, no qual já sempre nos encontramos como sujeitos de linguagem e ação, com a contingência de um desenvolvimento históriconatural das formas sócio-históricas de vida que constituem este mundo; b) A questão epistemológica do realismo: como conciliar a tese da pressuposição irrecusável de um mundo objetivo independente de nossas descrições e idêntico para todos os observadores com a tese básica da reviravolta linguística de que não temos acesso diretamente, isto é, não linguisticamente mediado, a uma realidade "nua".

$\mathrm{Na}$ modernidade, a teoria do conhecimento se havia transformado na nova "filosofia primeira" que herdou todas as dicotomias (interior $\mathrm{x}$ exterior, privado x público, vivência x discurso) do pensamento metafísico de origem platônica. Neste contexto, a reviravolta linguística iniciada por Frege e radicalizada por Wittgenstein consistiu, para Habermas, fundamentalmente na substituição de uma "análise mentalista" das sensações, representações e juízos por uma "análise semântica" das expressões linguísticas. ${ }^{50} \mathrm{Ela}$, em princípio, teria possibilitado um enfrentamento pragmático das questões epistemológicas levantadas por Hume e Kant.

De fato, isto não aconteceu por ter a análise da linguagem conservado a primazia, típica de toda a tradição de pensamento ocidental, dada

49 Para Haack, sob nenhuma condição, a justificação pode substituir a questão da verdade. O objetivo da investigação é a verdade substancial e mesmo os que explicitamente rejeitam a verdade como Rorty, defensor da tese de que o máximo que podemos alcançar é ter crenças justificadas e de que a justificação de nossas crenças nada tem a ver com a verdade, não podem evitar de apelar implicitamente à verdade. Cf. HAACK, S. Evidence and Inquiry: Towards Reconstruction on Epistemology. Oxford, 1993, p. 203 e ss.

50 Cf. HABERMAS, J. Wahrheit, op. cit., p. 8. 
à teoria frente à práxis, à sentença declarativa e à sua "função de apresentação" frente à sua "função comunicativa". Perdeu-se a novidade da reviravolta linguística através da concentração da investigação na estrutura da sentença declarativa, o que significou simplesmente a continuação da filosofia da consciência com instrumentos semânticos. Somente a reviravolta pragmática foi capaz de efetivar as virtualidades já presentes na primeira fase da reviravolta linguística e de considerar a linguagem em sua integralidade, uma vez que ela serve tanto para apresentação como para a comunicação, e o proferimento linguístico é, ele mesmo, uma forma de ação.

Habermas defende a tese da co-originariedade de apresentação, comunicação e ação como as dimensões constitutivas da linguagem o que significa dizer que a linguagem humana é sempre relação ao mundo e relação aos outros sujeitos. Foi M. Dummett, ${ }^{51}$ para ele, quem levantou explicitamente a questão da relação entre apresentação e comunicação e chegou à afirmação de que se tratam, aqui, de duas dimensões igualmente constitutivas da linguagem.

A partir deste pano de fundo, Habermas considera, como a tarefa mais importante da filosofia contemporânea, submeter a uma releitura pragmática a filosofia transcendental que pretendeu reconstruir as condições universais e necessárias sob as quais algo pode tornar-se objeto da experiência e do conhecimento. Trata-se, aqui, de conservar este conceito, desvinculando-o do conceito mentalista fundamental de autorreflexão e da concepção fundamentalista de a priori e a posteriori. A leitura pragmática do transcendental provoca uma deflação do pensamento de Kant de tal maneira que, agora, a análise transcendental significa a busca de condições presumivelmente universais e inevitáveis somente, de fato, que tornam os sujeitos capazes de linguagem e de ação aptos a participar de determinadas práticas e executar certas obras.

Não se tratam mais, aqui, de juízos da experiência, mas de tipos elementares de comportamentos regrados de tal modo que a análise transcendental vai tematizar as regras que subjazem aos mundos vividos como sua condição de possibilidade e que se encarnam nas práticas e nas obras destes sujeitos. É neste horizonte que, segundo Habermas pensa, também a hermenêutica que é fundamentalmente uma hermenêutica da finitude, uma vez que o sentido é constituído por uma subjetividade mergulhada em condições históricas de tal forma que o sentido constitui-se como fruto de nosso pertencer à história, embora a

51 Cf. DUMMETT, M. "Language and Communication". In: The Seas of Language. Oxford: Clarendon Press, 1993, p. 166. 
hermenêutica não tenha sido também capaz de tirar as consequências de suas intuições fundamentais. ${ }^{52}$

A análise transcendental busca os traços invariantes que retornam na pluralidade histórica de formas de vida socioculturais. Numa palavra, depois da reviravolta linguística, não podemos mais analisar nossa capacidade de conhecimento independentemente de nossa capacidade de falar e agir, uma vez que nós, como sujeitos cognoscentes, já sempre nos encontramos no horizonte de nossas práticas no mundo vivido. Linguagem e realidade estão mutuamente imbricadas de tal modo que toda experiência humana é linguisticamente impregnada.

Todos estes motivos levam-nos a atribuir um papel transcendental às condições intersubjetivas da interpretação linguística e do entendimento de modo que, no lugar da subjetividade transcendental da consciência, se põe a intersubjetividade destranscendentalizada do mundo vivido. Isto significa dizer que se transforma, aqui, radicalmente, o próprio conceito do que seja a esfera transcendental: a consciência transcendental não é mais pensada como constituindo algo transcendente, uma grandeza do mundo inteligível, mas desce à terra da práxis comunicativa quotidiana. Mesmo guardando a problemática transcendental, o pragmatismo transcendental vai enfraquecer a contraposição entre o transcendental e o empírico. Sem dúvida, o uso comunicativo da linguagem leva a idealizações: os falantes orientam-se em pretensões de validade incondicionadas que transcendem os contextos contingentes e simplesmente locais. Porém, todos estes pressupostos contrafatuais têm seu lugar na facticidade das práticas quotidianas, uma vez que é no próprio processo de socialização que os sujeitos apropriam-se das práticas e do saber correspondente a respeito das regras.

Tudo isto leva a uma releitura de conceitos centrais da tradição transcendental como o conceito de experiência que, agora, é pensado a partir da perspectiva de um sujeito participante de contextos de ação já linguisticamente mediados o que leva a duas mudanças fundamentais: 1) Supera-se definitivamente o "mito do dado", uma vez que a experiência sensível já é mediada linguisticamente ${ }^{53}$ de tal modo que ela perde sua autoridade epistêmica daquela instância que nos daria imediatamente a realidade pura; ${ }^{54}$ 2) A realidade é alcançada, agora,

52 Cf. HABERMAS, J. Wahrheit, op. cit., p. 12.

53 Habermas cita, aqui, a posição de Putnam para quem elementos do que chamamos linguagem ou mente penetram tão profundamente no que chamamos realidade que o projeto de considerar algo independente da linguagem já está fatalmente comprometido desde o ponto de partida. Cf. HABERMAS, J. Wahrheit, op. cit., p. 238.

${ }^{54}$ Foi mérito de W. Sellars em sua crítica ao empirismo do Círculo de Viena de ter explicitado esta consequência da reviravolta linguística. Cf. HABERMAS, J. Wahrheit, op. cit., p. 20. 
através do fracasso performativo de nossas práticas habituais e de nossas tentativas conscientes de intervenção de modo que o conhecimento deixa de ser entendido como uma representação de objetos a partir do material fornecido por nossas impressões sensíveis, imediatas para ser entendido como um "processo de aprendizagem" que é provocado pela problematização de expectativas que orientam as práticas de sujeitos imersos nos mundos vividos históricos.

Numa compreensão pragmática, o conhecimento é um comportamento inteligente que resolve problemas, corrige erros, destrói a força das objeções e, assim, possibilita processos de aprendizagem. A função de apresentação da linguagem, ao contrário, sugere a imagem enganosa de um pensamento que representa objetos e abstrai do contexto de experiências relativas à ação como também da dinâmica do aumento de saber através da problematização e das justificações discursivas.

A reviravolta pragmática traz um modelo de conhecimento contraposto ao modelo da representação, que é um modelo estático. Nossos conhecimentos constituem, na dimensão espacial, o resultado de nosso trabalho sobre as decepções em nossa convivência inteligente com um mundo cheio de riscos, na dimensão social, a partir da legitimação de soluções de problemas frente às objeções de outros participantes da prática argumentativa e, na dimensão temporal, a partir de processos de aprendizagem que se alimentam da revisão dos próprios erros. Considerando o conhecimento como função deste processo complexo, é possível compreender como aqui se imbricam dois movimentos: o movimento passivo da experiência do sucesso ou do fracasso prático e os momentos construtivos do projeto, da interpretação e da justificação.

Juízos de experiência formam-se nesses processos de aprendizagem e provêm das soluções dadas aos problemas. O conhecimento não acontece sem estas ações e mediações. Daí porque, numa perspectiva pragmática, a realidade não é algo a ser representado, mas se faz notar unicamente nas limitações a que estão submetidas nossas soluções para os problemas e os processos de aprendizagem. O modelo da representação é falho justamente por não levar em consideração o aspecto operativo do conhecimento: o domínio sobre problemas e o sucesso nos processos de aprendizagem. Sem dúvida, real é o que é o caso e o que pode ser representado em sentenças verdadeiras. Contudo, é na facticidade das limitações que se faz valer a resistência dos objetos que representamos quando afirmamos fatos sobre eles ${ }^{55}$. Habermas refere-se,

55 Uma tentativa de fundamentar as intuições realistas não através das limitações contingentes do mundo objetivo, mas através de uma espécie de realismo conceitual metafísico, ou seja, através da tese da sustentação de nossos conceitos num mundo 
neste contexto, à posição de Putnam sobre a pesquisa como processo de aprendizagem. ${ }^{56}$

Para ele, uma interpretação que, sob suas condições de conhecimento, era considerada aceitável, numa outra situação epistêmica, é considerada um erro, só constitui propriamente um processo de aprendizagem quando o fenômeno a ser explicado não se perde na passagem de uma interpretação para outra, ou seja, quando a relação ao objeto permanece invariável em suas diferentes descrições. Já na comunicação quotidiana, leigos e especialistas entendem-se mutuamente sobre o mesmo objeto a partir de suas diferentes perspectivas teóricas. Esta postura de Putnam, o "realismo pragmático", Habermas considera uma posição perfeitamente integrável em sua própria posição.

Ora, é precisamente o conceito de fracasso performativo que nos vai conduzir a uma pressuposição formal de nossas ações linguísticas e de nossas intervenções no mundo: um "mundo objetivo" como o sistema de possíveis referências, ou seja, como a totalidade de objetos que podem ser julgados e manuseados por nós. Assim, os participantes da ação instrumental e da ação comunicativa assumem a mesma pressuposição formal de um mundo independente de nós, de nossas descrições, de nossos esquemas conceituais.

A partir da resistência da realidade, podemos aprender algo na medida em que são tematizadas nossas convicções que, assim, são problematizadas. Tanto os autores da relação semântica aos objetos como os autores que enfrentam os desafios práticos fazem a mesma pressuposição pragmática, ou seja, a mesma pressuposição formal de um mundo objetivo independente de nós. Para Habermas, o uso do predicado "verdadeiro", no sentido de uma validade incondicional, significa que sentenças verdadeiras merecem ser aceitas como válidas por qualquer um em qualquer lugar. A esta universalidade da validade da verdade corresponde, do lado da referência, a suposição de que o mundo, qualquer que seja a perspectiva com a qual nos referimos a algo nele, permanece o mesmo e único mundo. Esta constitui, para ele, a análise da confrontação com o mundo que leva à aprendizagem desenvolvida por Putnam. ${ }^{57}$

Assim, a relação prática e a relação semântica com os objetos confrontam-nos com o "mundo", enquanto que a pretensão de verdade levantada pelas sentenças sobre os objetos confronta-nos com a possibilidade da contraposição dos outros. Desta forma, a relação vertical ao mundo objetivo, a objetividade do mundo, e a relação horizontal

estruturado conceitualmente em si mesmo, vê Habermas presente no pensamento de Brandom e McDowell. Cf. HABERMAS, J. Wahrheit, op. cit., p. 166.

56 Cf. HABERMAS, J. Wahrheit, op. cit., p. 44-45.

57 Cf. HABERMAS, J. Wahrheit und Rechtfertigung, op. cit., p. 152-153. 
aos membros de um mundo vivido intersubjetivamente partilhado, a intersubjetividade do entendimento, são mutuamente imbricadas. Os sujeitos, envolvidos em suas práticas, relacionam-se, a partir do horizonte de seu mundo vivido, em sua comunicação ou em suas intervenções, a algo no mundo objetivo que eles reconhecem como algo independente e idêntico para todo ${ }^{58}$ e enquanto algo que se distingue fundamentalmente da comunicação intersubjetiva.

Habermas tem consciência de que a deflação do esquema da filosofia transcendental kantiana, ou seja, a passagem de uma concepção transcendental-idealista para uma concepção transcendental-pragmática do transcendental, tem enormes consequências para a filosofia. Se as regras transcendentais não são compreendidas como algo inteligível fora do mundo, mas como algo que pertence aos mundos histórico-culturais, elas são, então, algo temporal. Isto significa dizer que não podemos mais pretender que a esfera transcendental garanta a universalidade e a necessidade, portanto, a objetividade de nossos conhecimentos. Além disto, enquanto tais, elas não são mais distintas do mundo, mas antes algo no mundo.

Numa palavra, a releitura pragmática da problemática transcendental traz de volta os problemas que Kant pretendia ter superado com sua filosofia transcendental, ou seja, o problema do relativismo e do ceticismo. Para Habermas, estas consequências paradoxais são decorrentes não tanto da releitura pragmática quanto da concepção de conhecimento como representação a que Kant permaneceu vinculado.

Aqui, põe-se a proposta própria de Habermas para a superação destes paradoxos: a vinculação da problemática transcendental-pragmática com um naturalismo fraco o que vai levar, com a afirmação do primado genético da natureza frente à cultura, a uma concepção epistemológica realista. Aqui, situa-se, para Habermas, o cerne da problemática filosófica contemporânea, ou seja, o desafio de pensar junto "primado epistêmico" do mundo linguístico, do mundo vivido com o "primado ontológico" de uma realidade independente da linguagem, que impõe limitações às nossas práticas. Neste campo, ele enfrenta dois principais adversários. Em primeiro lugar, o naturalismo forte ${ }^{59}$ de Quine que reduz todo tipo de conhecimento ao conhecimento das ciências empírico-analíticas o que

58 Putnam, segundo Habermas, combina um pluralismo teórico de descrições científicas com uma teoria do conhecimento de um realismo interno. Cf. HABERMAS, J. Wahrheit und Rechtfertigung, op. cit., p. 169-170.

59 Uma outra forma de naturalismo forte no contexto de uma interpretação materialista do pensamento de Kant, Habermas vê presente no pensamento do jovem Marx. Cf. HABERMAS, J. Erkenntnnis und Interesse. Frankfurt am Main: Suhrkamp, 1968, p. 36 e ss. OLIVEIRA, M. A. de. Filosofia na Crise da Modernidade. 3. ed. São Paulo: Loyola, 2001, p. 52-61. 
significa dizer que a análise conceitual das práticas do mundo vivido é substituída por uma explicação científica, neurológica ou biogenética. Desta forma, cai a distinção entre a reconstrução compreensiva de nossos mundos vividos e a explicação causal dos eventos no mundo objetivo.

Por outro lado, Heidegger que, fazendo da diferença ontológica entre ser e ente o cerne da reflexão filosófica, por um lado, historificou o próprio a priori do sentido sem com isto incorrer no perigo que se constitui quando a esfera transcendental coincide com o próprio fluxo das contingências intra-históricas. Por outro, defende uma espécie de um fatalismo de sentido que nos marca para além de nossa consciência, contrapondo-se, assim, à autocompreensão de seres autônomos que se movimentam através de razões na direção de tomadas de posição racionalmente motivadas.

O naturalismo fraco proposto por Habermas radica-se numa única pressuposição metateórica: nossos processos de conhecimento no quadro das formas de vida sócio-históricas, de alguma forma, dão continuidade a processos de aprendizagem evolucionários prévios que produziram as estruturas de nossas formas de vida. Nesta perspectiva, as estruturas transcendentais, que possibilitam nossos processos de conhecimento, revelam-se como resultado de processos de aprendizagem menos complexos de natureza histórico-natural e, através disto, adquirem seu conteúdo cognitivo. Esta postura não implica, contudo, qualquer tipo de reducionismo como é o caso do naturalismo forte. O naturalismo fraco distingue claramente a "perspectiva interior" do mundo de vida da "perspectiva exterior" do mundo objetivo. Ele só une as perspectivas teóricas que continuam diferenciadas no nível metateórico através da suposição da continuidade entre natureza e cultura.

É neste contexto que Habermas vai contrapor-se à forma de Pragmatismo elaborada por Rorty. Ele parte da mesma concepção de uma razão incorporada na linguagem: só podemos esclarecer o que é um fato com a verdade de um enunciado de fato que é efetivamente ${ }^{60}$, ou seja, a linguagem é condição irrecusável de nosso acesso ao mundo ${ }^{61} \mathrm{de}$ tal modo que não se pode considerar a experiência como uma instância de controle de nossos conhecimentos totalmente independente de nossos sistemas linguísticos, já que nos fornecem os esquemas cognitivos dos

${ }^{60}$ Cf. HABERMAS, J. Wahrheit und Rechfertigung, op. cit., p. 246.

${ }^{61}$ Cf. COSTA, R. da. "As vantagens de uma teoria consensual da verdade segundo Habermas". In: CIRNE LIMA, C.; ALMEIDA, C. (Orgs.). Nós e o Absoluto. Festschrift em homenagem a Manfredo Araújo de Oliveira. São Paulo, 2001, p. 377: "Ora para ele, a teoria da verdade como correspondência não se apercebe de que ao termo <realidade > não podemos dar nenhum outro sentido do que o que vinculamos aos enunciados sobre fatos e de que a 'realidade' só pode ser determinada mediante enunciados, ou seja, só no nível do discurso metalinguístico". 
objetos da experiência. Neste sentido, o conhecimento humano não pode transcender a esfera da linguagem para as coisas em si, porque a relação ao real já ocorre no seio da linguagem. Uma consequência imediata disto é que todas as questões filosóficas têm necessariamente que passar pela reflexão da linguagem sobre si mesma.

$\mathrm{Na}$ ótica da teoria do discurso, só podemos trabalhar a questão da verdade através do recurso à pragmática universal dos atos de fala. Uma ação linguística, nesta concepção, consta de dois momentos fundamentais: um momento performativo através de que se exprime o tipo de ação em questão (um determinado tipo de relação entre sujeitos) e o conteúdo proposicional, que exprime o estado de coisa (um saber de objeto). Isto significa que temos, então, que partir do contexto prático de comunicação e interação entre os sujeitos em seus mundos históricos como faz o pragmatismo que eliminou, através da ideia da mediação universal da linguagem, a concepção de verdade enquanto correspondência já que não podemos comparar a expressão linguística com um pedaço de realidade "nua", isto é, não linguisticamente mediada, ou seja, com um referente que esteja fora da mediação linguística.

No entanto, não se pode eliminar a pergunta pela relação do sistema linguístico à realidade por ele mediada, o que significa dizer que um aspecto da teoria da correspondência permanece presente na teoria do discurso. No entanto, para Habermas, o pragmatismo perdeu um aspecto essencial da problemática da verdade presente na teoria correspondencial, ou seja, a dimensão da validade incondicionada.

Daí a distinção fundamental que se impõe, neste contexto, entre as ações comunicativas da vida ordinária e o discurso. Na esfera de nossas ações linguísticas da vida cotidiana, informamo-nos sobre os objetos da experiência e as pretensões de validade incorporadas aos enunciados são implicitamente pressupostas e reconhecidas sem problemas, isto é, sem pôr em questão sua validade, pois a compreensão humana não pode funcionar sem que os diferentes parceiros relacionem-se a um único mundo objetivo e, com isto, estabilizem o espaço público intersubjetivamente partilhado do que se pode distinguir tudo o que é simplesmente subjetivo. Numa consideração da dimensão pragmática da linguagem, há um deslocamento das sentenças bem formadas para os proferimentos situados nos contextos de vida e para a competência comunicativa que lhes subjaz.

Então, ao invés de sentenças, o objeto de consideração são os atos de fala ou as ações linguísticas. Para todo sistema linguístico, há necessariamente, para Habermas, determinados tipos de atos: os comunicativos (exprimem o sentido da fala enquanto tal), os constatativos (exprimem o conteúdo proposicional), os representativos 
(autoapresentação) e os regulativos (exprimem normas). Com cada um destes tipos estão ligadas formas específicas de obrigações, o que significa dizer que com cada tipo de ato de fala levanta-se uma pretensão de validade específica.

Assim, por exemplo, quando faço uma afirmação, já assumi a obrigação, se por acaso for exigido, de apresentar os motivos da verdade do conteúdo proposicional de minha afirmação. ${ }^{62}$ Portanto, no nível em que se situa o pragmatismo, a pressuposição de um mundo objetivo é condição de possibilidade do funcionamento dos processos de cooperação e compreensão entre os seres humanos e, em nossos enunciados, afirmamos fatos sobre os objetos do mundo.

Habermas é consciente de que nem todo tipo de pragmatismo aceita esta intuição "realista" da vida cotidiana. Rorty, ${ }^{63}$ por exemplo, considera esta postura um engano e defende uma reeducação do homem comum através da substituição do desejo de objetividade pelo desejo de solidariedade e interpreta verdade como aquilo em que nós ocidentais cremos, nós, os membros liberais das sociedades de cultura ocidental.

No entanto, há, na própria vida cotidiana, uma necessidade "performativa" de certezas que exclui, em princípio, uma reserva de verdade. A força ilocucionária das afirmações não é a mesma nas ações e nos discursos: enquanto verdades no contexto da práxis cotidiana destruiriam as certezas da ação; no nível do discurso, elas constituem o ponto de referência, pois, no discurso, abandonamos os contextos concretos de ação para trocar argumentos sobre as pretensões de validade problematizadas, isto é, neste nível, põe-se explicitamente a questão da validade das pretensões, isto é, perguntamo-nos sobre o cumprimento das condições para a satisfação destas pretensões. Numa palavra, o uso do predicado "verdadeiro" mostra explicitamente que a pretensão foi cumprida, isto é, demonstrou-se intersubjetivamente legítima. Por esta razão, para Habermas, a questão da verdade não é um problema dos contextos de ação da vida cotidiana como afirma o pragmatismo, pois ela tem a ver com a problematização das pretensões de validade aí levantadas e seu resgate discursivo, ou seja, com a distinção entre opinião (o levantamento de uma pretensão da validade para o que é afirmado) e o saber (a solvência discursiva desta pretensão, ou seja, a demonstração das razões de legitimação) ser considerado como verdadeiro e ser verdadeiro.

62 Cf. HABERMAS, J."Vorbereitende Bemerkungen zu einer Theorie der kommunikativen Kompetenz". In: HABERMAS J.; LUHMANN N. Theorie der Gesellschaft oder Sozialtechnologie - Was leistet die Systemforschung? Frankfurt am Main: Suhrkamp, 1975, p. 111.

63 Cf. RORTY, R. "Is Truth a Goal of Enquiry? Davidson versus Wright". In: Phil. Quart. 45 (1995), p. 300. 
Isto pressupõe uma distinção fundamental que desaparece no pragmatismo, ou seja, a distinção entre a vivência das certezas da ação, das evidências da vida cotidiana, que têm suas raízes no vasto pano de fundo de convicções intersubjetivamente partilhadas (objetividade da experiência), e a afirmabilidade, discursivamente legitimada, de enunciados (verdade). Verdade revela-se, então, uma pretensão de validade que vinculamos a enunciados na medida em que os afirmamos. ${ }^{64}$

Portanto, a verdade é uma qualidade de enunciados, que só existe quando gerada por um ato de fala na medida em que é levantada uma pretensão, cuja validade precisa ser resgatada através de argumentos, o que significa dizer que o predicado de verdade pertence ao ato de fala da argumentação, isto é, aquele em que os participantes estão empenhados no esclarecimento de pretensões de validade cognitivamente solúveis através da apresentação de motivos (obrigação de fundamentação), com o fim de chegar a um consenso legitimado. ${ }^{65}$

O discurso tem, então, a tarefa de fazer passar de um acordo fático, casual e contingente para um acordo racional, isto é, conseguido através de um procedimento argumentativo, o que significa vincular-se à grande tradição do pensamento ocidental que vincula o conhecimento verdadeiro à sua fundamentação. ${ }^{66} \mathrm{~A}$ verdade é constituída, então, por três elementos fundamentais: a pretensão de validade, seu resgate discursivo e a relação aos objetos.

Isto implica uma passagem da ação para o discurso, o que provoca o desaparecimento do ter como verdadeiro ingênuo que caracteriza a vivência de certezas do nível dos contextos de ação e a transformação das afirmações anteriores em hipóteses, cuja validade tem que ser demonstrada através do processo argumentativo. Numa palavra, certezas do contexto de ação, que foram perturbadas por diferentes motivos, transformam-se no nível do discurso em pretensões de validade controversas de enunciados hipotéticos; estes precisam ser provados e, uma vez legitimados, podem retornar ao contexto de ação ${ }^{67}$, tornando

${ }_{64}$ Cf. HABERMAS, J. Wahrheitstheorien, op. cit., p. 129.

65 Para Höffe, as diferentes teorias consensuais da verdade têm alguns elementos comuns: a) Elas referem-se, exclusivamente ou em primeiro lugar, à verdade dos enunciados; b) Definem a verdade como um procedimento para a averiguação de enunciados verdadeiros; c) Este procedimento parte da situação do diálogo e está orientado para a efetivação de um acordo; d) Acordo não significa, em última instância, um evento histórico-fático, mas é entendido normativamente como consenso verdadeiro ou acordo objetivo; e) Como consenso verdadeiro vale o acordo potencial de todos ou de todos os que são competentes. Cf. HÖFFE, O. op. cit., p. 252.

66 Cf. PUNTEL, L. B. Wahrheitstheorien in der neueren Philosophie. Darmstadt: Wissenschaftliche Buchgesellschaft, 2. ed. 1983, p. 149.

${ }^{67}$ Habermas fala de um processo circular entre ação e discurso. Cf. HABERMAS, J. Wahrheit und Rechtfertigung, op. cit., p. 254. 
possível uma vida coletiva, agora, marcada pela verdade, isto é, por um consenso racional ${ }^{68}$.

Assim, o que distingue radicalmente a posição da pragmática universal do pragmatismo de Rorty é precisamente o papel da argumentação que separa claramente o processo de justificação nos contextos concretos de ação da verdade que implica um sentido incondicionado, independente do contexto de ação, isto é, que não pode ser relativizado a determinadas pessoas, grupos ou épocas, portanto, tem intrinsecamente uma pretensão à universalidade. ${ }^{69}$

\section{Referências}

AGUIAR, T. R. X de. "Realismo, construtivismo e progresso". In: MARGUTTI PINTO, P. R. et alii (Orgs.).

COMETTI, J-P. "Le Pragmatisme: de Peirce à Rorty". In: MEYER, M. (Org.). La Philosophie anglo-saxonne. Paris: PUF, 1994.

COSTA, R. da. "As vantagens de uma teoria consensual da verdade segundo Habermas". In: CIRNE LIMA, C.; ALMEIDA, C. (Orgs.). Nós e o Absoluto. Festschrift em homenagem a Manfredo Araújo de Oliveira. São Paulo, 2001.

DE WAAL, C. Sobrepragmatismo. São Paulo: Loyola, 2007, p. 238.

DUMMETT, M. "Language and Communication". In: The Seas of Language. Oxford: Clarendon Press, 1993.

GIANNOTTI, J. A. Apresentação do Mundo. Considerações sobre o pensamento de Ludwig Wittgenstein. São Paulo: Companhia das Letras, 1995.

HAACK, S. Evidence and Inquiry: Towards Reconstruction on Epistemology. Oxford, 1993.

. Manifesto of a Passionate Moderate. Chicago, 1998.

HABERMAS, J. Erkenntnnis und Interesse. Frankfurt am Main: Suhrkamp, 1968.

. "Vorbereitende Bemerkungen zu einer Theorie der kommunikativen Kompetenz". In: HABERMAS J.; LUHMANN N. Theorie der Gesellschaft oder Sozialtechnologie Was leistet die Systemforschung? Frankfurt am Main: Suhrkamp, 1975.

. "Wahrheit und Rechtfertigung. Zu Richard Rortys pragmatischer Wende". In: Wahrheit und Rechtfertigung. Philosophische Aufsätze. Frankfurt am Main: Suhrkamp, 1999.

HÖFFE, O. "Anhang: Kritische Überlegungen zur Konsensustheorie der Wahrheit (Habermas)". In: Ethik und Politik. Grundmodelle und probleme der praktischen Philosophie. Frankfurt am Main: Suhrkamp, 1979.

68 Que não se pode explicar através de motivos simplesmente lógicos ou através da evidência de experiências, mas através das propriedades lógico-formais do discurso. À lógica do discurso segundo Habermas pertencem antes de tudo três elementos: a) Um esquema determinado de argumentação; b) Crítica substancial da linguagem e autorreflexão; c) As condições da situação ideal de fala. Cf. HÖFFE, O., op. cit., p. 262.

69 Cf. HABERMAS, J. Vorbereitende Bemerkungen, op. cit., p. 124. 
HÖSLE, V. Hegels "Naturphilosophie" und Platons "Timaios" - ein Sturkturvergleich. In: Philosophiegeschichte und objektiver Idealismus. München: Verlag C. H. Beck, 1996. KOGLER, H-H. Die Macht des Dialogs. Kritische Hermeneutik nach Gadamer, Foucault und Rorty. Stuttgart, 1991.

LANDIM FILHO, R. Sobre a Verdade. In: Síntese Nova Fase. 20(63), 1993, p. 459-475. OLIVEIRA, M. A. de. Filosofia na Crise da Modernidade. 3. ed. São Paulo: Loyola, 2001. PEREIRA, A. M. Lendo Rorty Lendo Davidson, In: MARGUTTI PINTO, P. R. et alii (org.). PUNTEL, L. B. Wahrheitstheorien in der neueren Philosophie. Darmstadt: Wissenschaftliche Buchgesellschaft, 2. ed. 1983.

PUTNAM, H. Reason, Truth and History.

QUINE, W. V. Two Dogmas of Empiricism. In: AUDI R. (Org.). Epistemology Contemporary Readings. London/New York: Routledge, 2002.

RORTY R. "Nietzsche, Sócrates e o Pragmatismo". In: VIDAL, V.; CASTRO, S. de (Org. ). A questão da Verdade: da metafísica moderna ao pragmatismo. Rio de Janeiro: 7 Letras, 2006. 1982.

. Consequences of Pragmatism. Minneapolis: University of Minnesota Press, . Contingency, Irony and Solidarity. Cambridge: Cambridge Univ. Press, 1989. . Der Spiegel der Natur. Frankfurt am Main: Suhrkamp, 1981.

. "Is Truth a Goal of Enquiry? Davidson versus Wright". In: Phil. Quart. 45 (1995), p. 300. 1991.

. Objectivity, Relativism and Truth. Philosophical Papers I, Cambridge Univ. . Philosophical Papers, vol. I, Cambridge, 1991.

. Philosophy and Social Hope. London, 1999.

. "Pragmatismo, Filosofia Analítica e Ciência". In: MARGUTTI PINTO, P. R. et alii (Orgs.). Filosofia Analítica, Pragmatismo e Ciência. Belo Horizonte: Editora UFMG, 1998.

. Science et Solidarité. L 'Eclat, Combas, 1990.

. Solidarität oder Objektivität? Stuttgart, 1988.

. The linguistic Turn. Recent Essays in Philosophical Method. University of Chicago Press, Phoenix Edition, 1970.

SOUZA FILHO, D. M. de. Filosofia, Linguagem e Comunicação, São Paulo, 1984.

UTZ, K. Kontingenz Absolut. Richardd Rortys "Contingency, irony and solidarity" (mimeo). Tübingen, 2005.

WITTGENSTEIN L. Philosophische Untersuchungen. Frankfurt am Main: Suhrkamp. 